\title{
http://www.unibe.ac.cr/ojs/index.php/psicoinnova
}

\section{Beneficios de la Cámara de Gesell y Centro Internacional de Simulación Clínica (CISC) como estrategia pedagógica en el desarrollo de competencias y habilidades profesionales en estudiantes de bachillerato e psicología de la UNIBE.}

\section{Jorge Issac Ortíz \\ Universidad de Iberoamerica}

\section{Resumen}

La formación en psicología requiere que el estudiantado adquiera diversas competencias profesionales que se espera puedan aplicar en su campo profesional. En el área de la psicología clínica, es de vital importancia, para los docentes, lograr transmitir habilidades que provienen de la teoría y que puedan ser llevadas a la práctica. Es por esta razón que se describirá en el artículo, cómo la Facultad de Psicología de la UNIBE, ha recurrido al uso de entornos de simulación clínica, en múltiples cursos, para promover en sus estudiantes un aprendizaje por medio de la experiencia observacional, permitiéndoles así aplicar la teoría vista en clase y llevarla a la práctica. Lo anterior le permite al estudiantado beneficiarse de la supervisión y retroalimentación docente, con el fin de mejorar las competencias aprendidas en clase y llevarlas así a la práctica en situaciones reales.

Palabras clave: Simulación, Cámara de Gesell, Competencias profesionales, aprendizaje social. 


\section{Introducción}

Desde el año 2005, la Facultad de Psicología de la Universidad de Iberoamérica (UNIBE) ha hecho uso de la "Cámara de Gesell", en cursos tales como Sistemas de Psicoterapia, Psicodiagnóstico, Prácticas estudiantiles para entornos hospitalarios, entre otros. Ahora bien, durante el año 2016, a través de los cursos de Modificación de Conducta I y II, se comenzó a integrar el CISC como un espacio de simulación que permitiese ser utilizado como un recurso de aprendizaje al servicio del estudiantado de pregrado de la carrera de psicología.

En primer lugar es importante definir el tema de la simulación, lo anterior consiste en un medio que permite exponer al estudiantado a situaciones específicas, en un entorno controlado, promoviendo el desarrollo de habilidades y competencias a través de situaciones reales o hipotéticas, dentro del marco de un ambiente clínico y/o hospitalario (UNIBE, 2014).

El presente artículo se centra en el futuro uso de éste recurso institucional como parte de las estrategias pedagógicas utilizadas en los cursos Modificación de Conducta I y II. En dichos cursos se pretenderá que el estudiantado adquiera la capacidad para la aplicación de los elementos teóricos y prácticos de la terapia cognitivo-conductual para la evaluación e intervención de problemas psicológicos.

Como parte de los recursos didácticos del curso, se implementa el uso de la Cámara de Gesell como una importante herramienta de aprendizaje, apoyándose principalmente en la teoría del aprendizaje social de Bandura (1977). En dicho espacio el estudiantado podrá aplicar, en un entorno artificial y controlado, los conocimientos teóricos-prácticos vistos en clase y de esta manera reforzar el proceso de enseñanza en el desarrollo de competencias profesionales en el tratamiento e intervención de alteraciones cognitivas, emocionales y conductuales. 
En este artículo se describirá los orígenes y el uso de la Cámara de Gesell en la práctica y quehacer profesional de la psicología, así mismo se analizarán las posibilidades que ofrece este recurso dentro de los espacios pedagógicos y su utilidad para la enseñanza y la práctica de habilidades y destrezas profesionales.

\section{Cámara de Gesell}

Para entender la cámara de Gesell primero hay que entender el gran interés del psicólogo Arnold Gesell (1880-1961) en la observación como un método más eficaz para obtener información precisa, en sus estudios del desarrollo infantil. El Dr. Gesell se formó en una época donde el desarrollo tecnológico en la captación de imágenes estaba desarrollándose vertiginosamente. Él mismo fue un devoto aficionado a las posibilidades que ofrecía la tecnología fotográfica y la posibilidad de grabación y análisis, para su trabajo psicológico, en el contexto de la psicología del desarrollo. Sobre todo, le interesó el fenómeno de la permanencia, y de la memoria; de cómo, ante un estímulo visual se puede dejar una impronta más fuerte en el observador que cualquier otra explicación indirecta (Thelen y Adolph, 1992).

Esto lo llevó a desarrollar un curioso dispositivo: una cámara de estudio del comportamiento. Dicho dispositivo tenía el objetivo de poder realizar observaciones y experimentos a través de una pantalla o filtro por medio del cual se presencia lo que sucede en el interior de la cámara, sin que los sujetos del otro lado del vidrio puedan ver a los que están en el exterior (Thelen y Adolph, 1992).

En la actualidad, la cámara de Gesell, consiste principalmente en dos habitaciones, divididas por un vidrio grande que permite observar lo que sucede en solo una de las habitaciones. Gracias a lo anterior es posible llevar acabo, en un entorno controlado, múltiples 
modalidades de intervenciones psicológicas (ej. entrevistas, evaluaciones, observaciones, intervenciones clínicas, entre otros.).

Este recurso le permite a la psicología estudiar múltiples variables del comportamiento humano, observando no solo dinámicas individuales, sino también interacciones grupales (Salgado-García, 2012).

En la UNIBE, la Cámara de Gesell consiste en una habitación acondicionada con dos sillones y una mesa pequeña y del otro lado, dividido por el vidrio, hay escritorios para que los/las estudiantes observen las dinámicas realizadas, así mismo el equipo de sonido permite escuchar lo que sucede durante una intervención. Este espacio pertenece al CISC, que como centro de simulación, originalmente fue desarrollado para que el estudiantado pueda desarrollar habilidades y competencias en las ramas de medicina y enfermería, de la mano con los principales avances en estos campos (UNIBE, 2014).

Sin embargo, la estrategia conjunta de la Facultad de Psicología y del CISC, ha permitido el uso de dicho espacio para el desarrollo de herramientas y técnicas, implementadas en múltiples cursos de la carrera, como parte de una formación integral que promueva el contacto de estudiantes con escenarios cercanos a la realidad de los entornos clínicos.

Esto ha permitido que múltiples cursos utilicen dicho recurso como parte de las estrategias pedagógicas a disposición del personal docente. Ahora bien, en los cursos de Modificación de Conducta I y II, la Cámara de Gesell permite: a) modelar por parte del profesor técnicas y estrategias metodológicas vistas en el curso y b) por medio del role-play (juego de roles) llevar a cabo una dinámica en parejas donde uno de los estudiantes desempeña papel del terapeuta y el otro de paciente, utilizando casos clínicos (hipotéticos) asignados y supervisados por el docente. 
La estrategia anterior permite que el estudiantado que desempeña el rol de terapeuta pueda poner en práctica los conocimientos teóricos y habilidades vistas en el curso. Así mismo los demás estudiantes de la clase pueden observar dicho ejercicio desde la otra habitación y escuchar la interacción terapeuta/paciente, al mismo tiempo que el docente puede realizar intervenciones y comentarios sin interrumpir la simulación.

\section{Competencias Profesionales}

Para Salameo Nieto (2015) la competencia constituye un constructo multidimensional que comprende conocimientos y habilidades cognitivas que son inherentes a todo profesional. La autora separa estas competencias en dos grupos. El primer grupo se compone por las competencias genéricas serían los atributos comunes o compartidos en cualquier área de titulación entre las que encontramos: capacidad de análisis y síntesis, aplicación del conocimiento a la práctica, conocimientos generales básicos del campo de estudio, habilidades de gestión de la información, habilidades interpersonales, capacidad para trabajar de forma autónoma, habilidades informáticas básicas, habilidades de investigación, capacidad de aprender.

Con respecto a las del segundo grupo, las llama competencias específicas, son aquellas indispensables por la relación intrínseca con el área de estudio, y son las que confieren: "identidad y consistencia a cualquier programa conducente a la entrega de un título universitario" (Salameo-Nieto, 2015, p. 56). Las competencias se entienden entonces como la evidencia inmediata más clara que se tiene del desarrollo profesional de un estudiante desde el inicio de su formación de capacidades y habilidades universales académicas, hasta la especialización en un área, y su clara identificación dentro del área que le compete. 
Para Tejada-Fernández y Ruiz-Bueno (2016), las competencias representan un conjunto de conocimientos, procedimientos y actitudes que se llegan a combinar, coordinar e integrar, de manera tal que el individuo sea capaz de "saber", "saber hacer" y "saber estar", en relación con lo que implica el ejercicio profesional de su disciplina. Ahora bien, estos dominios son los que, posiblemente, le harían ser capaz de afrontar situaciones y/o problemáticas propias de su disciplina.

Este proceso de adquisición se puede imaginar en una figura piramidal ascendente según el modelo de niveles de Miller (1990), en donde describe en un nivel inferior los conocimientos (el saber y el saber cómo), y en la parte superior los comportamientos (el mostrar y el hacer). El paso de los conocimientos a los comportamientos se va a considerar, según el autor, como el criterio para medir la calidad profesional.

Tomando en cuenta lo anterior, es necesario justificar el acceso a estas competencias por medio de los procesos educativos y la exhaustividad con la que esas capacidades y habilidades se fortalecen por parte de las/los docentes.

Para Tabón-Tabón, Pimienta-Prieto y García-Fraile (2010), los/las docentes deben orientar sus acciones hacia la formación de competencias y no enseñar únicamente los contenidos, ya que éstos últimos son solo un medio para alcanzar dicho objetivo. Así mismo resaltan que las y los profesores deberían ser, principalmente, guías capaces de mediar el proceso de aprendizaje de sus estudiantes, para que éstos puedan aprender y reforzar las competencias que se les intenta transmitir.

Estas competencias profesionales, Charría-Ortiz, Sarsosa-Prowesk y Arenas-Ortiz (2012), las describen como aquellas que llegan a ser puestas en práctica durante el ejercicio de la actividad laboral, en este caso se relacionan con el quehacer profesional del psicólogo(a). Lo 
anterior implica que el aprendizaje de éstas mejora por medio de la experiencia directa, combinando los conocimientos teóricos y prácticos.

Por tal razón, es posible argumentar la importancia de considerar al menos dos niveles en la adquisición de competencias, donde se requerirá una fase de adquisición, y en segundo lugar una fase de demostración. Cabe entonces proponer que la Cámara de Gesell y el CISC se puede prestar precisamente como un método de enseñanza (por medio de la simulación) ideal para la exposición y demostración de conocimientos adquiridos, competencias y habilidades, dentro de un entorno pedagógico que simule un ambiente profesional, en el que se pueda ir identificando y mejorando los componentes de aquellas destrezas que se asocian con las competencias propias del profesional en psicología, según el énfasis del curso.

\section{Aprendizaje Social}

El aprendizaje social es un constructo teórico desarrollado por el psicólogo Albert Bandura y sus colegas durante los años 60s y 70s, su teoría llegó a ser ampliamente conocida y los aportes de sus investigaciones, en el campo del aprendizaje por observación han conservado su relevancia hasta la actualidad (Fryling, 2011).

El aprendizaje social, vicario o por observación es uno de los principios claves para comprender la teoría del aprendizaje social de Bandura. Su mayor impacto consiste en ampliar la perspectiva del enfoque conductual, tradicional, argumentando que a través de la observación o imitación de un modelo el sujeto puede aprender y adquirir una determinada secuencia de acciones complejas, o especializadas. Una de las principales conclusiones de los estudios de Bandura, es el hecho de que la conducta cambia por medio de la observación, incluso cuando ocurre de manera incidental (Fryling, 2011). 
Dentro la teoría del aprendizaje social se describe la importancia y el rol del modelaje, precisamente apelando a la posibilidad de estar expuesto a una figura que dirige o expone con precisión el comportamiento o acciones a seguir para que el observador le imite, dentro de un contexto determinado, considerando además aspectos cognitivos y simbólicos que, actualmente sabemos que juegan un rol fundamental en el aprendizaje.

Para Groenendijk, Janssen, Rijlaarsdam y van den Berg (2011), la observación representa el primer paso del proceso de aprendizaje. El observador emula el estilo general del modelo. Motivado por la retroalimentación que recibe del modelo, el aprendiz puede internalizar la habilidad y finalmente utilizar dicha estrategia de manera independiente en múltiples contextos.

Tomando en cuenta lo anterior, la cámara de Gesell y el CSIC ofrece, en este sentido, una posibilidad para poner a prueba las ventajas del modelado y poner en práctica los hallazgos de la teoría social de aprendizaje de Bandura. Es por medio de la exposición de modelos en vivo (docente, estudiantes), en un entorno controlado, que se puede estimular la adquisición de habilidades y competencias que requieren de un contexto donde sea posible combinar los conocimientos teórico-prácticos, ponerlos a prueba, recibir retroalimentación y aplicar las observaciones para mejorar las destrezas exhibidas.

\section{Discusión}

Desde la perspectiva profesional, la cámara de Gesell y el CISC facilita una representación o una simulación de un entorno "real" o "práctico", en el que eventualmente las/los estudiantes podrían llegar a enfrentar como parte de su campo profesional, donde 
además se espera sean capaces de mostrar y aplicar conocimientos teórico prácticos de su formación.

Por otro lado, este espacio, facilita al estudiantado observar los role-play, con la posibilidad de una retroalimentación inmediata, por parte del docente, por lo que el proceso es mejor asimilado, y comprendido por los estudiantes.

El docente debe desempeñar un rol de acompañamiento, presente desde el inicio hasta el fin del ejercicio, complementando las técnicas y metodologías, vistas en clase, dentro de un ensayo que permite integrar la teoría con la práctica.

A través de la cámara de Gesell y el CISC se posibilita el desarrollo de las competencias (anteriormente mencionadas) a partir de un proceso de prueba y error, que supervisado por el docente, permite al aprendiente poner en práctica lo aprendido, corregir aspectos señalados durante el ejercicio, e inclusive permite al profesor(a) aclarar dudas y/o consultas al resto de estudiantes que observan la intervención, sin llegar a afectar el proceso o interrumpir la dinámica del role-play.

\section{Referencias}

Bandura, A. (1977). Social learning theory. NJ, EE. UU, Prentice Hall.

Charría-Ortiz, V.H., Sarsosa-Prowesk, K. y Arenas-Ortiz, F. (2011). Construcción y validación de contenido de un diccionario de las competencias genéricas del psicólogo: académicas, profesionales y laborales. Interdisciplinaria Revista de psicología y ciencias sociales. 28(2), pp. 299-322.

Facultad de Psicología, UNIBE. (2014). Estrategia para uso de Sala de Simulación. 
Fryling, M.J. (2011). Understanding observational learning: an interbehavioral approach. The Analysis of Verbal Behavior. 27, pp. 19-203.

Groenendijk, T., Janssen, T., Rijlaarsdam, G. y van den Berg, H. (2011). The effect of observational learning on students' performance, processes, and motivation in two creative domains. British Journal of Educational Psychology. 1, pp. 1-26.

Miller, G. E. (1990). The assessment of clinical skills/competence/performance. Academic Medicine. 65 (9), pp. 63-67.

Salameo-Nieto, R.M. (2015). Utilidad de la cámara de Gesell en el desarrollo de las competencias profesionales del Psicólogo en la Universidad Técnica de Machala. I Congreso Internacional de Ciencia y Tecnología UTMACH 2015. Universidad Técnica de Machala, Equador

Salgado-García, E. (2012). Muybridge y Gesell: Pioneros de los métodos de investigación visual en Psicología. Revista Costarricense de Psicología. 31(5), pp. 191-210.

Tejeda-Fernández, J. y Ruíz-Bueno, C. (2016). Evaluación de competencias profesionales en educación superior: retos e implicaciones. Educación XX1. 19 (1), pp. 17-37.

Thelen, E. y Adolph, K.E. (1992). Arnold L. Gesell: The Paradox of Nature and Nurture. Developmental Psychology. 28(3), pp. 368-380.

Tobón-Tobón, S., Pimienta-Prieto, J.H. y García-Fraile, J.A. (2010). Secuencias didácticas: aprendizaje y evaluación de competencias. Juarez México, Prentice Hall. 